\title{
VARIÁ VEIS DETERMINANTES DA PRECIFICAÇÃO BASEADA NO VALOR PARA O CONSUMIDOR EM INSTITUIÇÕES DE ENSINO SUPERIOR PRIVADA
}

\section{DETERMINING VARIABLES OF PRICING BASED ON VALUE FOR THE CONSUMER IN PRIVATE HIGHER EDUCATION INSTITUTIONS}

\author{
Marlei Salete Mecca \\ Mestre em Administração \\ Universidade Federal do Rio Grande do Sul - UFRGS \\ Professora do Departamento de Administração e Ciências Contábeis do Instituto de Ensino \\ Superior da Grande Florianópolis - IESGF \\ Endereço: Rua João Amaral Rios, 573 - Apto 102 - Edifício Bay Wiev - Praia Comprida - \\ São José - Santa Catarina - Brasil - CEP 88103-475 \\ e-mail:msmecca@terra.com.br - Tel. (48) 3575615

\section{Romualdo Douglas Colauto} \\ Doutor em Engenharia de Produção \\ Universidade Federal de Santa Catarina - UFSC \\ Coordenador do Curso de Cềncias Contábeis do Instituto de Ensino Superior da Grande \\ Florianópolis - IESGF \\ Endereço: Rua XV de novembro, 150 - Apto 1307 Edifício Alzemiro João Vieira - Campinas \\ São José - Santa Catarina - Brasil - CEP 88101-440 \\ e-mail:rdcolauto@terra.com.br - Tel (48) 2417542

\section{Ilse Maria Beuren} \\ Doutora em Controladoria e Contabilidade FEA/USP \\ Coordenadora do Programa de Pós-Graduação em Ciências Contábeis da Universidade \\ Regional de Blumenau (PPGCC-FURB) - Santa Catarina \\ Endereço: Rua Antonio da Veiga, 140 - Victor Konder - Blumenau - Santa Catarina - Brasil \\ CEP 89010-500 - e-mail:ilse@ furb.br - Tel.(47) 3210565
}


RESUMO

Instituições de ensino superior privadas precisam avaliar os fatores críticos considerados pelos acadêmicos no momento da escolha da instituição, bem como monitorar as variáveis estratégicas determinantes no processo de satisfação dos consumidores. Assim, o artigo identifica as variáveis determinantes da precificação baseada no valor entregue ao consumidor em instituições de ensino superior privadas. Para tanto, realizoutse um estudo descritivo, por meio de uma pesquisa em três instituições de ensino superior privadas. Para a coleta dos dados utilizourse um questionário fechado, a fim de identificar os fatores determinantes da precificação fundamentada no valor para o consumidor, segundo o modelo de Philip Kotler. Os resultados da pesquisa mostram que as principais variáveis de valor total para o consumidor são a qualificação do corpo docente, qualidade do curso, retorno dos investimentos e adequação dos recursos físicos. Entre as variáveis de custo total para o consumidor foram apontados os horários de aulas, o tempo e custo com deslocamento, valor da mensalidade, as atividades complementares e a carga horária do curso.

Palavras-chaves: Precificação. Valor para o consumidor. Instituição de ensino superior privada.

\begin{abstract}
Private higher education institutions need to evaluate the critical factors as considered by academics in the choice of an institution, as well as to monitor the determining strategic variables that satisfy the consumers. From this perspective, this article identifies the determining variables of pricing based on the value given to the consumer by private higher education institutions. For this, a descriptive study was conducted through a survey of three private higher education institutes. A sealed questionnaire was used to collect data with the aim of identifying the determining factors of pricing based on consumer value following Philip Kotler's model. The research shows that the main variables of total value for the consumer are the qualifications of the teaching body, the quality of the course, the return on investment and the adequacy of physical resources. Amongst the total cost variables for the consumer, the lesson times, the time and cost of traveling, the monthly cost, complementary activities and total hours of the course were the determining strategic variables pointed out.
\end{abstract}

Keywords : Pricing. Consumer value. Private higher education institute.

\title{
1 INTRODUÇÃO
}

As mudanças provocadas pela evolução tecnológica e pelo desenvolvimento social e econômico dos países desafiam as organizações na capacidade de respostas às demandas macroambientais. Simultaneamente, as entidades necessitam identificar os fatores que precisam ser considerados para maximizar suas potencialidades e minimizar as ameaças, para manter a continuidade no mercado. Assim, as estratégias organizacionais devem convergir na 
sistematização de dados, na análise de concorrentes, identificação de competências essenciais e fatores de sucesso, com vistas a promover reflexos na performance financeira.

Uma das formas de otimizar o processo de gestão das instituições de ensino superior é monitorar continuamente os fatores de sucesso na consecução de planos estratégicos, pedagógicos e administrativos. Significa disponibilizar informações preditivas que subsidiem o processo decisório para cada situação. A identificação dos atributos considerados pelos consumidores na escolha das instituições de ensino permite focalizar estrategicamente as ações, com a finalidade de monitorar continuamente o ambiente sócioprodutivo em que atuam.

A diversidade de bens, serviços, marcas, preços e fornecedores contribuem para dificultar o processo de fidelização dos consumidores. Por conseguinte, a identificação da forma como os consumidores escolhem seus fornecedores ou prestadores de serviços parece caracterizar uma das áreas de interesses dos gestores. De acordo com Kotler (1998), os consumidores avaliam diversos atributos para optarem pela aquisição de determinado produto. Analisam, além do valor do produto, os valores dos serviços, dos funcionários e da imagem da organização. Após, comparam com o custo monetário, o custo do tempo despendido na aquisição dos produtos, a energia física e psíquica utilizadas no processo de compra.

Kotler (1998) afirma que as definições de mercado de um negócio devem ser superiores às definições de produtos. Um negócio precisa ser visto como um processo de satisfação do consumidor e não apenas como um processo de produção de bens e serviços. Explica que uma unidade de negócio precisa monitorar as forças macroambientais, como, os aspectos demográficos, econômicos, tecnológicos, políticos, legais, sociais e culturais; e ainda, os atores microambientais como, por exemplo, os consumidores, concorrentes, canais de distribuição e fornecedores que afetam as habilidades das organizações em obter os resultados planejados. Desse modo, as unidades de negócios devem estabelecer um sistema de 
informação para rastrear as tendências e desenvolvimento de bens e serviços. Para cada tendência e processo de desenvolvimento, cabe aos gestores identificar as ameaças e oportunidades associadas aos produtos, por meio do monitoramento dos fatores de sucesso do setor em que atuam.

De acordo com Ayres et al. (1999), a inserção da universidade, antes norteada apenas pelo enfoque acadêmico, em um modelo de gestão empresarial ${ }_{2}$ é premente a sua diferenciação no mercado. Conhecer as variáveis determinantes na estratégia observadas pelos consumidores em instituições de ensino superior privadas auxilia na gestão da precificação dos serviços universitários e possibilita visualizar os principais focos de atuação destas instituições para, concomitantemente, redirecionar estratégias competitivas. Nessa perspectiva, o artigo tem por objetivo identificar as variáveis determinantes na estratégia de precificação baseada no valor para o consumidor em instituições de ensino superior privadas.

O delineamento da pesquisa configura-se como um estudo descritivo, em que se utilizam fontes secundárias e primárias, com abordagem lógica dedutiva. As fontes secundárias consubstanciam-se de pesquisa bibliográfica para a formação do marco referencial teórico. As primárias originam-se de uma pesquisa em campo aplicada aos acadêmicos do curso de Administração de Empresas de três instituições de ensino superior privadas do Estado de Santa Catarina. Para a coleta de dados, optou-se por utilizar um questionário fechado usando o método de comunicação estruturado não-disfarçado, aplicado em novembro de 2004. A escolha dos sujeitos de pesquisas foi em função da acessibilidade aos dados necessários.

\section{ESTRATÉGIA DE PRECIFICAÇÃO BASEADA EM VALOR}


Valor era concebido pelos consumidores como uma combinação de qualidade e preço.

Com a evolução do conceito, passou a agregar, além de qualidade e preço, variáveis como a conveniência de compra, serviços pós-venda, imagem do produto, marca, atendimento, entre outras. Para Rossetti (2002), valor é um conjunto de dados de um produto. Assim, o consumidor tende a adquirir uma combinação que se traduza pela máxima utilidade total do produto. As quantidades das aquisições obedecem a decisões racionais, sob o pressuposto que, unidades adicionais de um mesmo produto à sua disposição recebem graus de utilidade decrescente. Ou seja, os consumidores agem de forma racional para maximizar sua satisfação.

A definição de preço pode ser vista como um componente crítico na estratégia de marketing, ao condicionar o faturamento e espelhar a percepção que o consumidor tem sobre os bens e serviços da empresa. Um mecanismo importante para a atuação gerencial se baseia no entendimento de relações de causa e efeito. Assim, é possível especificar um resultado desejado (efeito) e, então, manipular os mecanismos que se supõe provocar os resultados esperados (as causas). Para decisões assertivas faz-se necessário utilizar modelos para avaliar a influência das estratégias impetradas no negócio. Desse modo, a definição correta de preços deve avaliar as forças que moldam o mercado, a sensibilidade dos consumidores a preço, as interações com a concorrência e a situação interna da empresa (CRESSMAN JR, 2002).

O processo de precificação precisa começar com o entendimento de que os recursos mobilizados e utilizados no negócio têm como objetivo maior produzir valor. Em toda a organização, efetua-se uma transformação produtiva, na qual os recursos são convertidos em bens e serviços para os quais há uma demanda. Essa transformação deve produzir valor de duas naturezas distintas: a) valor para os clientes, que consiste nas características de desempenho e atributos que a empresa oferece na forma de bens e serviços, pelos quais os consumidores estão dispostos a pagar; e, b) valor para os investidores, buscando dar um retorno financeiro adequado aos recursos que aplicaram na empresa. 
Nas estratégias de definição de preço baseada em valor para o cliente, Kearney (2004, p.37) expõe que, primeiro, deve-se conhecer a definição de valor e, após, as maneiras de proporcioná- lo ao cliente. Explica que valor é um conceito subjetivo e determiná-lo constitui obstáculo durante o desenvolvimento de uma estratégia de precificação. "Se quem vende não consegue identificar o valor que o produto ou serviço proporciona ao comprador, o preço cobrado tende a ser irreal". Por outro lado, se o cliente não tem familiaridade com o produto que lhe é oferecido, não percebe uma razão clara e compensadora para seu investimento.

O valor refere-se à estimativa de satisfazer a um conjunto de necessidades humanas. Para Reis (2001. p.540), valor "é uma avaliação geral de utilidade do cliente baseada em suas percepções sobre o que está recebendo em relação ao que está dando". O cliente na percepção de valor recebido analisa qualidade, prazo de entrega, preço, conveniênc ia, reputação pessoal (status e prestígio), marca, reputação do fabricante e propaganda.

Segundo Kotler (1998, p.51), o valor entregue ao consumidor é a "diferença entre o valor total esperado e o custo total do consumidor. Valor total para o consumidor é o conjunto de benefícios esperados por determinado produto ou serviço. Custo total do consumidor é o conjunto de custos esperados na avaliação, obtenção e uso do produto ou serviço". Para identificação do valor entregue ao consumidor, utiliza uma fórmula que busca determinar quais são os atributos qualitativos e quantitativos considerados pelos consumidores do momento de suas decisões. Propõe que as organizações identifiquem, previamente, cada uma dessas variáveis para precificar os produtos. Na figura 1 apresentam-se os grupos determinantes de valores e custos, na ótica do valor entregue aos consumidores. 


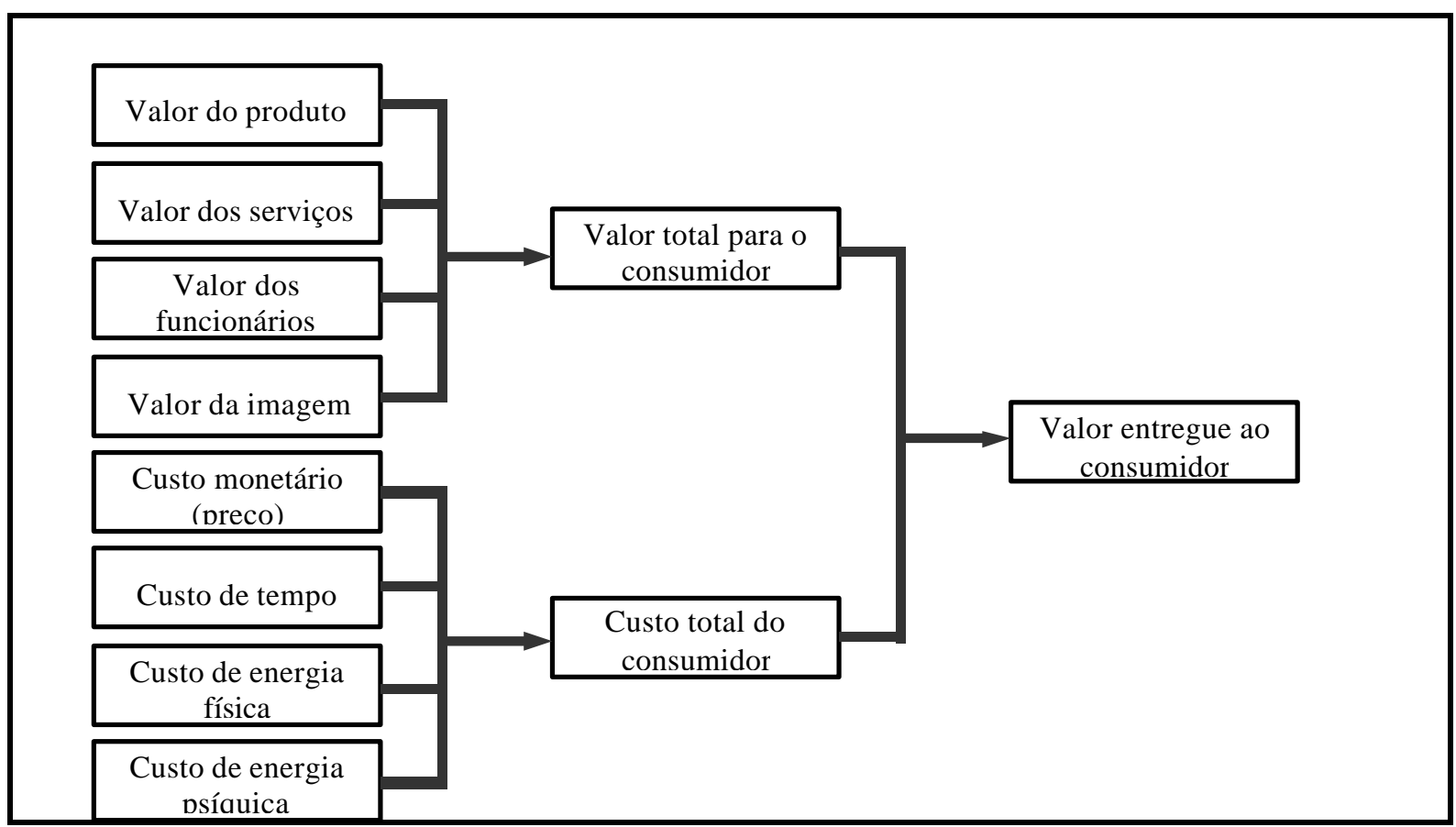

Figura 1: Determinantes do valor entregue ao consumidor Fonte: Kotler (1998, p.52)

De acordo com Kotler (1998), aumentar o valor total entregue ao cliente, requer a prédisposição das organizações em aumentar o valor total para o consumidor, melhorando os benefícios de produtos, serviços, funcionários e imagem ou, diminuindo o custo total por meio da redução do custo de tempo, custo de energia física, custo de energia psíquica e, por último, redução do custo monetário.

$\mathrm{Na}$ estratégia de precificação baseada no valor, as organizações podem entregar maior valor ao consumidor aumentando o valor total ou diminuindo o custo total. Para aumentar o valor total ao consumidor, devem contemplar variáveis que atendam aos níveis de confiabilidade, durabilidade, desempenho, entrega, treinamento e manutenção, oferecendo assim melhores serviços. Em instituições de ensino superior, a identificação prévia das variáveis estratégicas que determinam o valor total para o consumidor auxilia a otimizar o processo de gestão e monitorar continuamente os fatores de sucesso. 
De acordo com a proposta de Kotler (1998), além das variáveis que contemplam o valor total, o consumidor examina também o custo total que inclui o custo monetário (preço), custo de tempo, de energia física e psíquica. Para Kearney (2004, p 39), "a estratégia do custo monetário (preço) identifica o valor máximo que o comprador se dispõe a pagar em troca dos benefícios que recebe (ou percebe) do produto ou serviço". O custo de tempo envolve todo o processo, desde o pedido até a entrega do produto. E, o custo de energia física e psíquica envolve todo o esforço de aquisição.

A identificação das variáveis consideradas pelos consumidores no momento da compra, auxilia as instituições de ensino superior na gestão e elaboração do planejamento estratégico e na precificação de seus bens e serviços. Além disso, auxilia também na identificação das ameaças e oportunidades por meio do monitoramento dos fatores de sucesso determinantes na estratégia de precificação baseada no valor para o consumidor.

\section{DESCRIÇÃO E ANÁLISE DOS DADOS}

As instituições nas quais se realizou a pesquisa desenvolvem atividade de ensino superior, sendo duas situadas na cidade de Florianópolis e uma em Criciúma, ambas no Estado de Santa Catarina. As instituições de ensino encontram-se em estágio de implantação dos cursos, justificando assim a identificação das variáveis determinantes de valor na percepção dos consumidores para a elaboração do planejamento estratégico e precificação das mensalidades.

Quanto aos procedimentos de coleta de dados, optoutse por aplicar um questionário fechado, com cinco alternativas, aos alunos do curso de Administração de Empresas, a fim de identificar as variáveis consideradas pelos acadêmicos na escolha da instituição. Da população de 242 alunos, obteve-se 102 respostas. 
Para identificação dos atributos considerados relevantes pelos acadêmicos no momento da escolha da instituição e do curso, a pesquisa propôs cinco alternativas de respostas. Por meio das respostas pode-se avaliar se as instituições estão entregando valor aos consumidores, segundo o modelo proposto por Philip Kotler. Por conseguinte, possibilita analisar quais variáveis os consumidores percebem como diferenciais de sucesso na instituição. Conhecendo-se os atributos diferenciais de sucesso na percepção dos consumidores, pode-se delinear a importância desses no processo de precificação de mensalidades.

Na primeira alternativa, "concordo totalmente", considera-se que o acadêmico não apresenta nenhuma restrição quanto ao enquadramento das variáveis propostas como determinantes de sua escolha pela instituição. Referente à alternativa "concordo", apesar de ser um fator de sucesso, apresenta alguma restrição. Com relação à opção "indiferente", o acadêmico declina uma posição de indiferença pela variável. O item "não concordo" denota que o cliente apresenta alguma restrição quanto à inserção da variável como fator de sucesso. Por último, na opção "discordo totalmente" mostra restrições suficientes para não considerar o item como fator de sua escolha.

$\mathrm{Na}$ tabela 1 identificam-se as variáveis propostas para identificar se essas representam determinantes de valor na percepção dos acadêmicos.

\begin{tabular}{|c|c|c|c|c|c|}
\hline DETERMINANTES DE VALOR & $\begin{array}{l}\text { Concordo } \\
\text { totalmente }\end{array}$ & Concordo & Indiferente & Discordo & $\begin{array}{l}\text { Discordo } \\
\text { totalmente }\end{array}$ \\
\hline \multicolumn{6}{|l|}{ VALOR DO PRODUTO } \\
\hline Qualidade do curso & $11,40 \%$ & $46,70 \%$ & $21,90 \%$ & $12,40 \%$ & $7,60 \%$ \\
\hline Retorno do investimento & $13,30 \%$ & $36,20 \%$ & $25,70 \%$ & $16,20 \%$ & $8,60 \%$ \\
\hline \multicolumn{6}{|l|}{ VALOR DOS SERVIÇOS } \\
\hline Adequação dos recursos físicos & $2,90 \%$ & $38,10 \%$ & $27,60 \%$ & $16,20 \%$ & $15,20 \%$ \\
\hline Número de alunos por sala & $2,90 \%$ & $18,10 \%$ & $23,80 \%$ & $27,60 \%$ & $27,60 \%$ \\
\hline \multicolumn{6}{|l|}{ VALOR DO DOS FUNCIONÁRIOS } \\
\hline Qualificação do corpo docente & $15,20 \%$ & $48,60 \%$ & $21,0 \%$ & $8,60 \%$ & $6,60 \%$ \\
\hline Serviços administrativos e suporte técnico & $3,80 \%$ & $35,20 \%$ & $36,20 \%$ & $13,30 \%$ & $11,50 \%$ \\
\hline \multicolumn{6}{|l|}{ VALOR DA IMAGEM } \\
\hline Tradição da instituição & $2,90 \%$ & $16,20 \%$ & $26,60 \%$ & $23,80 \%$ & $30,50 \%$ \\
\hline Promoção de eventos & $2,80 \%$ & $21,00 \%$ & $36,20 \%$ & $25,70 \%$ & $14,30 \%$ \\
\hline
\end{tabular}


Tabela 1 - Determinantes de valor total para o consumidor

Fonte: dados da pesquisa

Segundo a proposição de Kotler (1998), os determinantes de valor total para os consumidores consubstanciam-se nos benefícios almejados por um certo bem ou serviço. Nesse sentido, as variáveis que devem ser analisadas pelas organizações estão relacionadas ao produto, ao serviço, funcionários e ao valor da imagem.

Com relação às variáveis que identificam o valor do produto, nota-se que $58,10 \%$ dos acadêmicos escolheram a instituição em função da qualidade oferecida pelo curso e 21,90\% dos questionados mencionaram estar indiferentes com relação a esta variável. Ressalta-se que a qualidade do curso diz respeito à legitimidade do vestibular, do processo seletivo, foco da grade curricular e as atividades pedagógicas. O item, "retorno do investimento", mostra que 49,50\% têm preocupação com a previsão de retorno e 50,50\% dos acadêmicos parecem não estar atentos ou preocupados com os valores empreendidos em sua formação.

Nos determinantes do valor dos serviços, foi questionado sobre a adequação dos recursos físicos da instituição. A adequação dos recursos físicos faz alusão aos laboratórios de informática, empresa júnior e aos acervos bibliográficos. Nota-se que apenas $41 \%$ atentaram para este fator. Quando perguntados se o número de alunos por sala influenciou na opção pela instituição, somente $21 \%$ declinaram concordar e concordar totalmente com esta variável.

Para identificar o valor dos funcionários pesquisou-se a qualificação do corpo docente e a qualidade dos serviços administrativos e de suporte técnico. Com relação à primeira pergunta, 63,80\% dos acadêmicos observaram e pontuaram como importante a titulação dos professores. Para a segunda opção, 3,80\% concordam totalmente que a qualidade dos serviços administrativos e técnicos influenciou sua escolha. Por outro lado, 36,20\% e 24,80\% mostraram-se indiferentes e não concordaram, respectivamente com a variável. 
As variáveis do valor da imagem analisaram a tradição da instituição e os eventos

promovidos. Destaca-se que a promoção de evento diz respeito aos congressos, seminários, encontros e simpósios realizados durante a consecução do curso. Para o item tradição, constatou-se que somente $19,10 \%$ dos acadêmicos perceberam isto como diferencial. Vale ressaltar que este percentual pode estar relacionado ao início da implantação dos cursos. Por sua vez $76,20 \%$ demonstraram estar indiferentes ou não concordar que a promoção de eventos colaborou para a escolha da instituição. O percentual conota que os acadêmicos desconhecem a importância de atividades extracurriculares na preparação para o mercado de trabalho.

A etapa de definição das variáveis determinantes do valor entregue ao consumidor propõe que se analise o custo total do consumidor para obtenção dos bens e serviços. Na tabela 2 apresenta-se o resultado da pesquisa para as variáveis propostas na identificação de tais fatores determinantes, segundo a percepção dos acadêmicos. 


\begin{tabular}{|c|c|c|c|c|c|}
\hline DETERMINANTES DE CUSTOS & $\begin{array}{l}\text { Concordo } \\
\text { totalmente }\end{array}$ & Concordo & Indiferente & Discordo & $\begin{array}{c}\text { Discordo } \\
\text { totalmente }\end{array}$ \\
\hline \multicolumn{6}{|l|}{ CUSTO MONETÁRIO } \\
\hline Valor da mensalidade & $27,60 \%$ & $34,30 \%$ & $11,40 \%$ & $16,20 \%$ & $10,50 \%$ \\
\hline Custos com deslocamento & $47,50 \%$ & $22,80 \%$ & $14,90 \%$ & $7,90 \%$ & $6,90 \%$ \\
\hline \multicolumn{6}{|l|}{ CUSTO DE TEMPO } \\
\hline Horários de aulas adequados & $42,30 \%$ & $36,50 \%$ & $10,60 \%$ & $5,80 \%$ & $4,80 \%$ \\
\hline Tempo de deslocamento & $43,30 \%$ & $29,80 \%$ & $16,30 \%$ & $4,80 \%$ & $5,80 \%$ \\
\hline \multicolumn{6}{|l|}{ CUSTO DE ENERGIA FÍSICA } \\
\hline Carga horária total do curso & $8,60 \%$ & $36,20 \%$ & $32,40 \%$ & $10,50 \%$ & $12,30 \%$ \\
\hline Carga horária diária do curso & $10,50 \%$ & $36,20 \%$ & $28,60 \%$ & $13,30 \%$ & $11,40 \%$ \\
\hline \multicolumn{6}{|l|}{ CUSTO DE ENERGIA PSÍQUICA } \\
\hline Atividades complementares & $8,60 \%$ & $45,70 \%$ & $28,60 \%$ & $11,40 \%$ & $5,70 \%$ \\
\hline Exigências para conclusão do curso & $4,80 \%$ & $22,90 \%$ & $41,90 \%$ & $15,20 \%$ & $15,20 \%$ \\
\hline
\end{tabular}

Tabela 2 - Determinantes do custo total do consumidor

Fonte: dados da pesquisa

O determinante custo total do consumidor representa o conjunto de custos na obtenção e uso de bens e serviços. Assim, para analisar os determinantes do custo total do consumidor, verifica-se o custo monetário, o custo de tempo, de energia física e energia psíquica despendidos para realização do curso.

No grupo do custo monetário, a pesquisa mostrou que $61,90 \%$ dos acadêmicos concordam ou concordam totalmente que o valor da mensalidade influenciou quando da escolha pela instituição e, 70,30\% consideraram os custos necessários para o deslocamento até a instituição. Destaca-se que este grupo de questionamentos mostra a influência do custo monetário das mensalidades e do deslocamento no processo de escolha das instituições de ensino. Observa-se que os custos monetários representam um fator de sucesso crítico para a competitividade das instituições de ensino pesquisadas.

O segmento que analisou o custo de tempo mostrou que 78,80\% dos acadêmicos levaram em consideração a adequação do horário das aulas às suas atividades profissionais. E ainda que, 73,10\% observaram o tempo necessário para o deslocamento até a instituição. 
As variáveis sobre o custo de energia física analisam o esforço necessário para a conclusão do curso superior. Nesse aspecto, 43,80\% observaram a carga horária total e 46,70\% a diária quando da escolha do curso e da instituição. No que se refere ao custo de energia psíquica, contemplou-se questionamentos acerca das atividades complementares e exigências para conclusão do curso. As atividades complementares estão relacionadas ao envolvimento dos acadêmicos em projetos voltados à comunidade externa e a trabalhos extracurriculares que corroboram para a formação acadêmica como, por exemplo,os cursos de idiomas, convênios para estágio, atividade desportiva, programa de iniciação científica. Assim observou-se que $54,30 \%$ dos questionados declinaram conhecer a necessidade do envolvimento das instituições de ensino superior com o ambiente externo. Os trabalhos exigidos para conclusão do curso foram considerados por $41,90 \%$ dos alunos como fator indiferente na sua opção e 30,40\% discordaram e discordaram totalmente que este fator teve influência na escolha.

Uma organização centrada no consumidor está interessada em rastrear e avaliar continuamente a satisfação dos consumidores potenciais. Os fatores determinantes do valor entregue ao consumidor ajuda delinear quais os fatores de sucesso que os gestores acadêmicos devem percorrer para agregar valor ao negócio. A partir da pesquisa ${ }_{2}$ pode-se constatar que algumas ações das instituições estão centradas em determinantes do custo total do consumidor, e outras em determinantes de valor, conforme se apresentam na tabela 3.

\begin{tabular}{l|c}
\hline \multicolumn{2}{c}{ DETERMINANTES DE VALOR TOTAL PARA O CONSUMIDOR } \\
\hline VARIÁVEIS DETERMINANTES & PERCENTUAL \\
\hline Qualificação do corpo docente & $63,80 \%$ \\
\hline Qualidade do curso & $58,10 \%$ \\
\hline Retorno dos investimentos & $49,50 \%$ \\
\hline Adequação dos recursos físicos & $41,00 \%$ \\
\hline \multicolumn{1}{c|}{ DETERMINANTES DO CUSTO TOTAL PARA O CONSUMIDOR } \\
\hline Horário de aulas adequado & $78,80 \%$ \\
\hline Tempo de deslocamento & $73,10 \%$ \\
\hline Despesas com deslocamento & $70,30 \%$ \\
\hline Valor da mensalidade & $61,90 \%$ \\
\hline Atividades complementares & $54,30 \%$ \\
\hline Carga horária diária do curso & $46,70 \%$ \\
\hline
\end{tabular}


Tabela 3 - Principais determinantes de valor entregue ao consumidor

Fonte: dados da pesquisa

A identificação dos fatores críticos de sucesso na percepção dos clientes, conforme demonstrado na tabela 3, busca ampliar o escopo dos fatores críticos de sucesso das instituições para alinhar o planejamento estratégico às necessidades dos clientes e assim precificar seus produtos e serviços de forma competitiva.

O valor entregue ao consumidor é determinado pelo preço que a organização cobra na venda de bens e serviços. A precificação ocorre por meio da identificação e mensuração de variáveis que compõem o custo total para o consumidor e o valor total para o consumidor. Conhecendo quais variáveis são determinantes no custo e no valor, na percepção do consumidor, viabiliza disponibilizar bens e serviços que atendam aos anseios dos mesmos e criem diferenciais competitivos para a instituição.

A pesquisa constatou que os acadêmicos identificaram maior número de variáveis que definiram as suas escolhas pelas instituições de ensino superior no grupo de determinantes do custo total para o consumidor, conforme apresentados na tabela 3, referindo-se, principalmente, ao horário de aulas adequado, ao tempo e despesas com deslocamento, valor da mensalidade, atividades complementares, carga horária total e diária. Como variáveis determinantes do valor total para o consumidor, apontaram, entre outras, a qualificação do corpo docente, qualidade do curso, retorno dos investimentos e adequação dos recursos físicos.

As instituições devem utilizar e explorar estas variáveis identificadas pelos acadêmicos na precificação dos bens e serviços como fatores críticos de sucesso. Por outro lado, as variáveis pouco citadas na pesquisa podem compor o quadro de estratégias prementes para melhorar a representatividade da instituição no mercado. Por fim, a definição dos 
atributos considerados pelos consumidores na decisão da compra, possibilita às instituições de ensino superior identificarem as ameaças e oportunidades pelo monitoramento dos fatores de sucesso, visualizar os principais pontos de atuação para redirecionar estratégias competitivas e, identificar as variáveis determinantes na estratégia de precificação baseada no valor entregue ao consumidor.

\section{CONCLUSÕES}

Os consumidores adquirem produtos das empresas que oferecem maior valor. $\mathrm{O}$ valor para o consumidor é definido como a diferença entre o valor total para o consumidor e o custo total para o consumidor. A partir desta comparação obtém-se os valores entregues aos consumidores. Isso significa que os fornecedores ou prestadores de serviços precisam focar suas estratégias para avaliar o valor total oferecido por seus produtos, uma vez que a satisfação do comprador está associada ao desempenho percebido do produto e de suas expectativas.

O estudo sobre as variáveis determinantes da precificação baseada no valor entregue ao consumidor em instituições de ensino superior privadas envolveu uma pesquisa em campo, que possibilitou identificar os fatores que são observados pelos acadêmicos no momento da decisão por uma instituição de ensino. Entre as variáveis consideradas como determinantes de valor total para o consumidor em instituições de ensino superior estão: qualificação do corpo docente; qualidade do curso; retorno dos investimentos e adequação dos recursos físicos. Com relação às variáveis apontadas como determinantes de custo total para o consumidor obtevese: horário de aulas adequado; tempo de deslocamento; despesas com deslocamento; valor da mensalidade; atividades complementares; carga horária diária do curso; carga horária total do curso. 
Para aumentar o valor total entregue ao consumidor, as organizações podem aumentar o valor total para o consumidor melhorando os benefícios de produtos, serviços, funcionários e imagem; ou diminuindo o custo total por meio da redução do custo de tempo, custo de energia

física, custo de energia psíquica e, por último, redução do custo monetário. Por fim, se o consumidor não tem familiaridade com o valor do produto ou serviço que lhe é oferecido, não percebe uma razão clara e compensadora para seu investimento e, então, provavelmente não realizará o investimento.

\section{REFERÊNCIAS}

AYRES, F. A. et al. (1999) - Base conceitual e prática para implementação de um sistema de inteligência competitiva em uma universidade particular. In: Workshop Brasileiro de Inteligência Competitiva e Gestão do Conhecimento, I, 1999. Rio de Janeiro. Anais... Rio de Janeiro-RJ: FINEP, CD-ROM.

CRESSMAN JR. G. (2002) A definição de preço na prática. HSM Management, São Paulo, v. 1, n.33, p.74-82, jul./ago.

KEARNEY, A.T. (2004) O que os consumidores valorizam? HSM Management, São Paulo, v. 1, n.44, p.36-43, mai./jun.

KOTLER, P. (1998) - Administração de marketing: análise, planejamento implementação e controle. 5. Edição. Atlas: São Paulo.

REIS. H. L. (2001) Análise econômica das iniciativas da qualidade. In: CATELLI, A.

(Coord.). Controladoria: uma abordagem de gestão economia GECON. 2. Edição. Atlas: São Paulo, p. 81-109.

ROSSETI. J.P. (2002) - Introdução à economia. 19a Edição. Atlas: São Paulo.

\section{Artigo recebido em 15/06/05 e aceito para publicação em 20/06/05}

